4 Virginia Pallante ${ }^{\mathrm{a}}$, Pier Francesco Ferrari ${ }^{\mathrm{b}}$, Marco Gamba $^{\mathrm{c}}$, Elisabetta Palagi ${ }^{\mathrm{a}, \mathrm{d}}$ 5

6

$7 \quad{ }^{a}$ Natural History Museum, University of Pisa, Via Roma 79, 56011, Calci, Pisa, Italy

8 bInstitut des Sciences Cognitives Marc Jeannerod, CNRS/Université Claude Bernard Lyon 1, 67 Bd $9 \quad$ Pinel, 69675 Bron Cedex, France

10 'Department of Life Sciences and Systems Biology, University of Torino, Via Accademia Albertina 1113,10123 , Torino, Italy

12 dUnit of Ethology, Department of Biology, University of Pisa, Via A. Volta 6, 56125, Pisa, Italy 13

Corresponding author: elisabetta.palagi@unipi.it

17 Key words: geladas, female closeness, embracing variability, grooming 
In several primate species, including humans, embracing predicts the level of affiliation between subjects. To explore the functional meaning of embracing we selected Theropithecus gelada as a model species. The basic level of gelada society is the one-male unit and the integrity of the group is maintained by the strong bonds between females. In our study group, we observed three different kinds of embracing: the Frontal and Side Embraces involving a face-to-face and chest-to-chest interaction and the Posterior Embrace which consists in putting the arms around conspecifics' back and posing a cheek on it. We verified whether the quality of relationships between subjects predicts the type of embracing. Frontal and Side Embraces were more frequent between females sharing strong bonds. Posterior Embracing was randomly distributed. We found a high level of female embracing among the mothers during the first months of lactation. This may improve female cohesiveness against males thus limiting the risk of infanticide, particularly high in geladas. Embracing seems also to act as an ice-breaker favoring grooming. In conclusion, female embracing could be an affiliative strategy which has evolved to maintain group integrity and high social cohesion among females, especially mothers, who mostly need it.

Keywords: geladas; female closeness; embracing variability; grooming 
Embracing is a behavior that produces positive physical and emotional experiences (Boeving, Belnap \& Nelson, 2017; Clay \& de Waal, 2013; de Waal, 1996, 2000; Forsell \& Åström, 2012). In children and apes, embracing is used to provide comfort to others (de Waal, 2012) and it has been proposed that it may communicate sympathetic concern (de Waal, 2008; Fujisawa, Kutsukake \& Hasegawa, 2006). In some non-human primate species, embracing behavior may be part of greeting rituals and functions as a tension-reduction mechanism. Embracing is reported in greeting ceremonies (black-and-white colobus, Colobus guereza, Kutsukake et al., 2006; hamadryas, Papio hamadryas, Colmenares, 1991; spider monkeys, Ateles geoffroyi, Schaffner \& Aureli, 2005; Guinea baboons, Papio papio, Whitham \& Maestripieri, 2003) and increases after a period of separation in species living in fission-fusion societies (spider monkeys, Schaffner \& Aureli, 2005; chimpanzees, Pan troglodytes verus, Okamoto, Agetsuma, \& Kojima, 2001). These particular societies are characterized by temporal separations and subsequent re-unions of the subjects of the same group (Symington, 1987). The spreading of embracing after fusion events has a role in reducing the risk of aggression (spider monkeys, Aureli \& Schaffner, 2007; Schaffner \& Aureli, 2005). In short, it seems to be involved in the management of risky and uncertain encounters (spider monkeys, Rebecchini, Schaffner \& Aureli, 2011; Guinea baboons, Whitham \& Maestripieri, 2003; capuchin monkeys, Cebus apella, Lynch Alfaro, 2008). Embracing also plays a role in reducing tension around preferred resources. Spider monkeys frequently embrace each other to co-feed peacefully (Pastor-Nieto, 2001). In the same species, when females have young infants, embraces are used by other females to gain access to infants and manipulate them (Schaffner \& Aureli, 2005; Slater, Schaffner \& Aureli, 2007).

Embracing does not only have immediate consequences to gain preferred resources but it can reflect and/or potentiate social bonding between individuals in the long-term. Tonkean macaques (Macaca tonkeana) use clasping (sensu Thierry, 1984; including grasping, embracing, hugging and reaching around) in various contexts to appease (immediate consequence), re-establish and maintain 
good relationships after conflicts (long-term function) (Thierry, 1984). In muriquis, (Brachyteles arachnoides hypoxanthus) male-male hugging is a specific reproductive strategy adopted before the mating period, presumably to reduce tension over limited resources (the females) during the mating period (Strier, Dib \& Figueira, 2002). Moreover, muriqui males engage in embracing to maintain peaceful long-term relationships (Strier, Carvalho \& Bejar, 2000).

Theropithecus gelada is a good primate model to investigate embracing, since this behavior is frequent and highly variable in its expression (Figure 1). Geladas are characterized by male dispersal and female philopatry (Kawai, Dunbar \& Ohsawa, 1983; le Roux, Beehner \& Bergman, 2011). They live in a multi-level society in which the basic social group is a one-male reproductive unit (OMU) including an alpha male, several reproductive females, sub-adult males and females, infants and juveniles (Snyder-Mackler, Beehner \& Bergman, 2012). Both the alpha male and females are responsible for managing social interactions and maintaining the unity of the group (Pallante, Stanyon \& Palagi, 2016; Palagi, Leone, Demuru \& Ferrari, 2018). The alpha male engages in a high level of affiliation with all group members, even though he does not reach the level shown by females (Bramblett, 1970; Mori, Belay \& Iwamoto, 2003; Mancini \& Palagi, 2009; Palagi, Leone, Mancini, \& Ferrari, 2009; Dunbar, 2014). In fact, group stability depends on the strong bonds shared among females, which form the core of the social unit. Their bonds rely on mutual grooming, playing, supporting each other during conflicts and providing reciprocal infant care (Dunbar, 1983, 2014; Dunbar \& Dunbar, 1975; Bernstein, 1975; Mancini \& Palagi, 2009; Pallante et al., 2016). Female affiliation is also revealed by the presence of yawn contagion and rapid facial mimicry, two phenomena of neural-motor resonance that is an index of the emotional proximity between subjects independently from their genetic relatedness (Mancini \& Palagi, 2009; Palagi et al., 2009). Gelada females have a linear, maternally inherited dominance hierarchy, whose steepness is weak if compared to other baboon species (le Roux et al., 2011). Due to the peculiar 
affiliation pattern shown by gelada females, we expect that embracing should be more common between females than between males and females.

In primates, different kinds of embraces can communicate different levels of bonding between subjects (Lynch Alfaro, 2008; Strier et al., 2002; Whitham \& Maestripieri, 2003). Notably, nonhuman primates embrace both frontally (symmetric; both individuals display a reciprocal embrace while engaging in a face-to-face interaction, Frontal Embracing (FE) and Side Embracing (SE) Fig. $1 \mathrm{a}$ and $1 \mathrm{~b}$ ) and at the back (asymmetric; one individual embraces the other from the back, Posterior Embrace, PE; Fig. 1c). For example, in olive baboons (Papio cynocephalus anubis, Smuts \& Watanabe, 1990) and in hamadryas (Papio hamadryas, Colmenares, Hofer \& East, 2000) the subordinate subject presents the posterior to the dominant, which responds with an embrace at the back. Therefore, the occurrence of asymmetric embrace (Posterior Embrace) seems to be predictive of the relative ranking position of the two interacting individuals. If in geladas the Posterior Embrace has the same function as the one recorded in the genus Papio, we expect the distribution of the Posterior Embrace to be affected by the ranking position of the two subjects, with the higher ranking individual embracing the posterior of the subordinate. A study on lateralization of face-toface embracing (left cheek vs right cheek) in Ateles fusciceps rufiventris has recently demonstrated that this behavior is modulated by emotional states (Boeving et al., 2017). In humans, during an embrace between strangers and acquaintances the number of body areas contacted is moderate, while it is higher among friends and between lovers (McDaniel \& Anderson, 1998). If in geladas, the reciprocal embracing involving a face-to-face interaction and a large body part (Frontal and Side Embrace; Figure 1a and 1b; Supplementary Video S1 and S2) is predictive of the social closeness between the subjects, rather than by the ranking status, we expect that the phenomenon is affected by the relationship quality of the individuals involved.

In addition to be a behavioral index of the relationship quality among individuals, embracing might also further sustain bonds under circumstances in which the environment is perceived as 
dangerous for the individuals, thus requiring group cohesion and coordinated responses. For example, for a female a highly vulnerable period coincides with the delivery of newborns because of the risk of infanticide perpetrated by males or predation (wild geladas, Beehner \& Bergman, 2008; captive geladas, Pallante et al., 2016; Papio ursinus, Palombit, Cheney, Fischer, Johnson, Rendal et al., 2000: Papio hamadryas Henzi \& Barrett, 2003). Barrett, Halliday \& Henzi (2006) demonstrated that to cope with the costs of motherhood, female baboons (Papio hamadryas ursinus) increased their vigilance levels during the lactation period (the first 4 months after the delivery). In different species of baboons (Papio spp.) living in multi-male/multi-female societies, male-female "friendship" can act as a deterrent for infanticide to occur (Palombit, Seyfarth, \& Cheney, 1997; Smuts, 1985). In geladas, living in one male units, females can form alliances with other females against the alpha male (Dunbar \& Dunbar, 1975). Females coalitions have a strong adaptive value, since infanticide perpetrated by alpha males is not rare in geladas and in our study colony (Pallante et al., 2016). Therefore, during the first months of maternal phase in geladas, the mothers can gain advantage from seeking social support and cohesion from other adult females. If this hypothesis is correct, we expect that when a female has a black infant, which is a newborn aged less than 4 months (lactating period), she would be more prone to initiate/accept embracing towards/by other females.

In the current study we will also assess the potential functional role of embraces in relation to gain access to other females' infants, a phenomenon widely described in the genus Papio (Frank \& Silk, 2009; Henzi \& Barrett, 2002; Silk, Rendall, Cheney \& Seyfarth, 2003). In Papio cynocephalus ursinus, infant handling is a behavior responding to the biological market rules and it can be exchanged for grooming (Henzi \& Barrett, 2002). Even though females without infants provide high levels of grooming to mothers in order to gain access to their infants (Henzi \& Barrett, 2002), mothers are attracted by other mothers' infants and try to handle them at relatively high rates. Embracing seems also a phenomenon responding to the biological market rules and is performed to 
136 increase the probability of accessing to infant, as it has already reported for spider monkeys

137 (Schaffner \& Aureli, 2005; Slater et al., 2007). If embracing is a behavior performed by gelada 138 females to increase the probability to gain access to other females' infants, we expect that the 139 lactating mothers (black infant $<4$ months) receive more embracing than non-mothers (offspring $>$ 14014 months).

In primates, behaviors such as grooming, may act as a means to strengthen relationships among group members. Grooming has been shown to reflect positive dyadic interactions and often acts as social glue within many primate societies (Dunbar, Barrett, \& Lycett, 2005; Schino, Scucchi, Maestripieri, \& Turillazzi, 1988). For example, in black and white colobus embracing has been reported to strengthen social affiliation by increasing the probability for grooming to occur (Kutsukake et al., 2006). If also in geladas embracing favors grooming, we expect that an embrace, more than the mere approach between two subjects, would increase the probability to engage in a grooming session. committee of the University of Pisa and Parma waived the need for a permit.

\section{Subjects and Data Collection}

We observed two colonies for a total of 40 geladas housed at the NaturZoo (Rheine, 157 Germany). The groups were composed of two one-male units (OMUs). For each subject, the exact date of birth was known. We identified animals through sex, age and distinctive external features 
categorization (Table 1) we followed Dunbar \& Dunbar (1975). Adult females were 9 in OMU 1 and 7 in OMU 2 (Table 1). All maternal kin relationships were known (Table 1).

The two OMUs were set in two different enclosures. Each of the enclosures included an indoor (about $36 \mathrm{~m}^{2}$ ) and an outdoor facility $\left(2700 \mathrm{~m}^{2}\right.$ surrounded by a boundary ditch). The monkeys had continuous access to the indoor and outdoor areas of their enclosures. The outside enclosures were located in an open, naturally hilly area equipped with trees, where environmental enrichments like branches, ropes and dens were provided. The food (grass, vegetables and pellets) was distributed twice a day (9:30 a.m., 2:30 p.m.). Water was available ad libitum. No stereotypic or aberrant behaviors have ever been observed in this group.

Before starting the data collection, the four observers underwent a training period of about 30 h. The training ended when the Cohen's kappa was always higher than 0.70 for each behavioral pattern considered for the study. We checked for observation reliability at the beginning of each month obtaining values always above 0.70 .

Animals were observed for 2 three-months periods: in 2010 (June-August) and in 2011 (JuneAugust). Observations were carried out by four observers with the aid of voice recorders and video cameras. Grooming was recorded via focal animal sampling.

Focal subjects were observed for 30 min each observation day. We focused on one OMU per day. Therefore, all the subjects of a single OMU were observed at least ones per day (see Table 1 for details on the observed subjects). The observations were balanced across the 6hrs observation period in order to be sure not to follow the same animal at the same time of the day in consecutive days. Moreover, the $6 \mathrm{hrs}$ observations were equally spread between morning and afternoon. If the same embrace was recorded by two different observers who were following two distinct animals that embrace each other, the behavior was recorded by both the observers but it was counted as a single event in the analysis. 
All occurrences sampling technique (2010: 301.5 hours; 2011: 267.4 hours) was used to collect data on embracing (based on video recordings). We observed three different types of embracing (Figure 1).

Animals spontaneously formed subgroups ranging from 3 to 7 subjects. One observer continuously video-recorded all the activity of the subjects forming a single subgroup. Before starting the video analysis, we checked for observation reliability each 3 hs-time block of recording obtaining values always above 0.75 .

To build the dominance matrix, all agonistic interactions (chase-fleeing, aggressive pulling/pushing, slapping, biting) were collected by sampling all occurrences. We recorded the opponents' identity for each agonistic encounter. The outcome of decided conflicts (with clear winners and losers) was used to calculate dominance scores.

We divided the adult females according to the lactating phase. Female who were lactating their infants (black infants; $<4$ months) were clustered as "lactating mothers" (Barrett et al., 2006; Dunbar, Hannah-Stewart \& Dunbar, 2002). In the first 4 months of life, black infants depend almost exclusively on mothers for food. Females who had yearlings/juveniles aged $>4$ months were clustered as "nonlactating mothers" (Dunbar \& Dunbar, 1975).

\section{Operational Definitions and Statistical Analysis}

The observations carried out in 2010 and 2011 permitted us to analyze the influence of the presence of black infants on mothers' behavior. We compared the hourly frequency of embracing events initiated by the same mother in two different situations (lactating vs nonlactating) (all occurrences sampling based on video data collection). Due to the non-normal distribution of data, we used Wilcoxon test to compare the two conditions. 
Social bonding was determined dividing the number of grooming sessions $(>10 \mathrm{sec})$

performed by an actor $\mathrm{X}$ toward a receiver $\mathrm{Y}$ by the total number of grooming session performed by X toward everybody (XgrY/XgrALL) (Girard-Buttoz et al., 2014).

Kinship was based on maternal lineages (kin coefficient: $r \geq 0.25$, paternal sisters excluded) (Table 1).

Hierarchy was assessed by entering decided conflicts involving individuals into a winner/loser socio-matrix. Rank was measured by Normalized David's Scores. Normalized David's scores (NDS) were calculated on the basis of a dyadic dominance index (Dij) in which the observed proportion of wins (Pij) is corrected for the chance occurrence of the observed outcome. The chance occurrence of the observed outcome is calculated on the basis of a binomial distribution with each animal having an equal chance of winning or losing in every dominance encounter (de Vries, Stevens, \& Vervaecke, 2006). The correction is necessary when, as in the case of our study groups, the interaction numbers greatly differ between dyads. Rank hierarchies were calculated including only adults. After calculating the Normalized David's Score values (NDS), we expressed as the NDS difference (deltaNDS) the status rank difference between the actor and the receiver.

We ran a General Linear Mixed Models (GLMMs) using the lme4 package (Bates et al., 2015; version 1.1.17) in $\mathrm{R}$ ( $\mathrm{R}$ Core Team, 2015; version 3.4.4) to test which variables could affect the distribution of the different kinds of embracing (face-to-face/chest-to-chest embracing FE+SE; Posterior Embracing, PE; Figure 1; Table 2). We checked variance inflation factors (VIF) using the car package (Fox \& Weisberg, 2011) and found that all VIF were below 2, showing the absence of collinearity. We ran a first GLMM to test whether the likelihood of embracing FE+SE (Table 2) was influenced by the difference in rank between the individuals (deltaNDS), by the level of social bonding within the dyad, and by the mothering status of the partners (mother vs. non-mother). We built the model using the number of $\mathrm{FE}+\mathrm{SE}$ events as the response variable, the minutes of observation as offset (after log-transformation), the rank difference between the partners, the level 
of social bonding, the mothering status of the partners $(0=$ nonmother-nonmother; $1=$ nonmothermother; $2=$ mother-nonmother; $3=$ mother-mother) as fixed factors, the level of kinship between the partners $(0=$ nonkin; $1=$ kin $)$ as a control predictor, and identity of the actor, identity of the partner, and the year of observation as random factors. We verified the assumptions that the residuals were normally distributed and homogeneous by looking at a qqplot and the distribution of the residuals plotted against the fitted values (using a function written by R. Mundry). Once excluded the collinearity between predictors (see Estienne et al. 2017), we tested the significance of the full model (Forstmeier \& Schielzeth, 2011) by comparing it against a null model comprising the control predictor and the random factors only, by using a likelihood ratio test (Anova with argument test "Chisq"; Dobson, 2002). We calculated the P values for the individual predictors based on likelihood ratio tests between the full and the respective null model by using the R-function "drop1" (Barr et al., 2013; Mundry \& Nunn, 2009; Mundry, 2011). Then, we ran a second GLMM with the same predictors, controls, and random factors, which included the number of PE (Table 2) as the response variable, to test whether the likelihood of PE was influenced by the same factors.

To assess whether the presence of embracing $\left(\mathrm{AP}_{\text {embracing }}\right)$ favored the initiation of a grooming session compared to a simple approach between the subjects ( $\mathrm{AP}_{\mathrm{NO}}$-embracing), we ran a binomial GLMM. We used the presence/absence of grooming as the dependent variable $(0=$ absent; $1=$ present $)$, presence/absence of embracing after an approach as a predictor $(0=\operatorname{absent} ; 1=$ present $)$, kinship, bonding, deltaNDS, and mothering status of the partners as control factors. We entered the identity of the actor, identity of the partner, and the year of observation as random factors (Table 3). We used the same steps presented above to test the model and derived the significance of the single predictors.

\section{Results}


Embracing is a phenomenon which involved exclusively adult and subadult females. Therefore, we focused subsequent analyses on females only. Adult females performed both face-toface/chest-to-chest embracing (FE $\left.+\mathrm{SE}_{\text {mean hourly frequency } \pm \mathrm{SE}}=0.0102 \pm 0.00118\right)$ and Posterior Embracing $\left(\mathrm{PE}_{\text {mean hourly frequency } \pm \mathrm{SE}}=0.0027 \pm 0.00051\right)$.

In our first model investigating which variables affected the likelihood of embracing $\mathrm{FE}+\mathrm{SE}$, the full model was significantly different from the null model. Face-to-face/chest-to-chest embraces were more frequent between mother-mother dyads and positively influenced by the strength of their bond (Table 4; Figure 2 and 3). On the other hand, kinship had a negative effect on the number of embraces, as FE + SE were more spread among non-kin females (Table 4).

In our second model investigating which variables affect the likelihood of embracing PE the full model was not significantly different from the null model. When comparing the full versus the null model using the likelihood ratio test for the PE, we did not find any significant difference (Full vs Null: Chisq $=8.644, \mathrm{df}=5, \mathrm{P}=0.124)$. Thus, we could not proceed calculating the significance of the single predictors.

Since our study covered two years, we had the possibility to gather data on the same seven females in two different conditions: when they were lactating (0-4 month black infant) $v s$ when they were not lactating (the same mother without any black infant). The comparison revealed that when the females changed their status they concurrently also changed their levels of embracing. When the females were lactating they engaged in higher levels of face-to-face/chest-to-chest embracing than when they were not lactating (Wilcoxon's $\mathrm{T}=1.00 ;$ ties $=0 ; \mathrm{N}=7 ; \mathrm{p}=0.028$ ).

Due to the random distribution found for the Posterior Embracing (PE), to test the prediction about the role of embracing in facilitating grooming interaction, we focused the analysis on the face-to-face/chest-to-chest embracing (FE+SE). We found that the full model including response, predictor, control factors and random factors significantly differed from the model including 
response against the random factors (null model). The occurrence of embracing, but not the other predictors, had a significant effect on the onset of grooming (Table 5).

\section{Discussion}

In the current study, we showed that in geladas embracing is exclusively performed by adult females who engaged in this behavior more frequently during the first months of lactation (Figure 3). Social bonding did affect the distribution of the different embracing patterns (Figure 1). Compared to Posterior Embrace, Frontal and Side Embraces, involving face-to-face and chest-tochest interactions, were more common between strongly bonded (Figure 2) and non-kin related females.

In humans, different forms of touching can communicate different emotional states (Hertenstein, Keltner, App, Bulleit, \& Jaskolka, 2006). Studying human embracing, McDaniel \& Anderson (1998) found that the number of body areas entering in contact was higher among friends and lovers. For example, in humans warm touching and embracing often signal an individual's prosocial motivation and cooperative intent (Frank, 2002; Hertenstein et al., 2006). The different types of embraces in geladas also seem to convey different meanings. Frontal (face-to-face) and Side (chest-to-chest) Embraces (Figure 1a and 1b), contrary to Posterior Embracing, were more frequent between subjects sharing strong social bonds (Figure 2). In contrast, Posterior Embracing (Figure 1c), the asymmetric form, was randomly distributed. Thus, the type of embrace can predict the quality of relationships between adult gelada females. In this view, human and gelada embracing seem to show some interesting common functional features. The similar use of embracing involving a face-to-face/chest-to-chest interaction between strongly bonded subjects underlines that for both species this behavior probably plays an important role in maintaining goodquality of relationship, or friendship. 
From a functional point of view, embraces in geladas appear to have a similar role to that observed for grunts in baboons. In female baboons (Papio cynocephalus ursinus) grunt vocalizations signal a benign intent favoring immediate affiliative contacts (Cheney, Seyfarth, \& Silk, 1995). Interestingly, grunts facilitate social interactions especially among unrelated females. As it occurs for grunts in baboons, in geladas embraces are exchanged more frequently between non-kin than between kin females. By embracing each other, unrelated females probably reinforce their cohesion thus coping with potential unpredictable interactions. This is particularly important in geladas, whose relationships are not based on nepotism but rely on the strength of social bonds.

The link between face-to-face embracing and grooming is strengthened by their temporal association. A grooming session was more likely to occur after an embrace than after a simple physical approach, independently from the characteristics of the partners. This result is in line with the hypothesis that behaviors which can be potentially risky (during an embrace animals expose vulnerable body areas, i.e. head and ventrum) function as 'ice-breakers' and facilitate the occurrence of grooming (Cheney et al., 1995, Kutsukake et al., 2006).

On the contrary, the Posterior Embracing seemed not to be affected by any variables considered for the analysis, including the NDS values of the subjects. Our result contrast with previous observations on baboons, where high ranking subjects embrace the back of subordinates who present the posterior (Colmenares, 2000; Smuts \& Watanabe, 1990). The fact that Posterior Embracing is not affected by rank can be explained by the very shallow hierarchical steepness in geladas. In this species, hierarchy is fluid and plays a less central role in social dynamics and group organization compared to baboons, especially among females, whose social bonds represent the most important glue of the society. However, since Posterior Embracing was observed at very low frequency, this hypothesis needs further support by additional data collections on other colonies.

The higher activity in embracing behavior recorded between gelada mothers during the lactating phase supports the view that this phenomenon is associated to specific phases of females' 
life cycle. In mammals, the endocrine changes occurring during the first phase of lactation seem to be one of the proximate factors influencing females' responsiveness towards their infants (Maestripieri, 2001). Human and non-human mothers interact emotionally with their newborns through mutual gaze (Ferrari, Paukner, Jonica \& Suomi, 2009; Stern, 1985; Trevarthen, 1974, 1980; Tronick, 1989) and touch stimulation (Palagi, 2018). This positive affective process can then encompass different types of social interactions, from the mother-infant one to adult-adult interactions (either with kin or non-kin individuals), thus expanding such affective exchanges to other social domains. Our findings on embracing behavior of mothers during lactation support this view. During the lactation period human and non-human primate mothers produce high levels of plasma oxytocin, which has been reported to increase the motivation to engage in behaviors fostering social attachment (Feldman, Weller, Zagoory-Sharon, \& Levine, 2007; Levine, ZagoorySharon, Feldman, \& Weller, 2007; Light, Grewen \& Amico, 2005; Simpson, Sclafani, Paukner, Hamel, Novak, et al., 2014). This could be one of the proximate mechanisms which sustains the high frequency of embracing behaviors we assessed between gelada lactating mothers. This hypothesis clearly requires further investigation as it has also important implications for our understanding of the mechanisms regulating social behaviors in nonhuman primates.

Even though specific analyses on infant handling are not provided here, we cannot exclude a link between embracing among mothers and infant access. For instance, Silk et al. (2003) observed that female baboons (Papio cynocephalus ursinus) were more attracted by other infants when they had their own infants. Again, the functional similarity between grunts in baboons and embracing in geladas appears evident. Females of chacma baboons grunts more frequently to mothers compared to non-mothers and the use of grunts increases the access to others' infants (Silk, Seyfarth, \& Cheney, 2016). As for grunts, embraces may function as a tension reduction mechanism which creates the condition for social interaction to occur especially when the interacting subjects share uncertain relationship (Silk et al., 2016). In this view, we cannot exclude that embracing may play a 
role in facilitating infants' access and be part of the biological market linked to infant handling also in such a female-bonded and tolerant species.

From a functional perspective embracing may be an adaptive behavior favored by natural selection; in some primate species females are highly prone to form strong social networks, which can ensure higher survival and fitness (Furuichi, 2011; McFarland \& Majolo, 2013; Seyfarth \& Cheney, 2013). Embracing in geladas is particularly frequent during the first months of lactation, when females can benefit from others' females support to better protect their infants from potential infanticidal males. Interestingly, in some species of baboons living in multi-male/multi-female society, females can reduce infanticide risks by increasing their bonds with males and thus supporting each other in defending the offspring (Smuts, 1985; Palombit et al., 1997). In wild savannah baboons, Silk and co-workers (Silk, Alberts \& Altmann, 2003) found that females affiliate with other females to limit the harassment by males and enhance infant survival (Barrett et al., 2006). Geladas live in a female-bonded society and one of the core factors strongly affecting their fitness is female strong affiliation and agonistic support also against males (Dunbar, 2014; Pallante et al., 2016). In our studied colonies we have reported some cases of infanticidal behaviors perpetrated by males (Pallante et al. 2016) and we observed one infanticide event also during our data collection. We therefore hypothesize that female affiliation in geladas can be a potential tool to prevent the infanticide perpetrated by males, a common phenomenon in this species (Beehner $\&$ Bergman, 2008; Mori, et al., 2003; Pallante et al, 2016). This hypothesis is also supported by our data showing that embracing increased during the first four months of lactation (black infants), a high-risk period for infanticide. The finding that embraces are more spread among unrelated females is essential in this sense. During an attack by the alpha males, a female receives more frequently aid by her kin, given the inclusive fitness benefit that the supporter would gain from her intervention (Hamilton, 1964). On the other hand, gelada females may exchange embraces with non-kin in order to strengthen bonds with unrelated subjects and, as a consequence, increase a 
potential cooperation with them. This mechanism is particularly important to maintain good relationships among non-kin, given that the benefit provided by the aid of an unrelated subject relies on reciprocal altruism more than on genetic advantages (Hamilton, 1964). In this perspective, by increasing their levels of embracing gelada females may strengthen their cohesiveness against potentially infanticidal males, and thus limiting the risk of losing their offspring.

In conclusion, in geladas the different types of embracing can have different meanings. The embraces characterized by a face-to-face and chest-to-chest interaction are exclusive to adult females which share strong bonds. The bonding hypothesis clearly requires further investigations in order to understand whether this females' strategy could be one of the possible mechanisms at the basis of the maintenance of group cohesion, also in absence of the dominant male.

\section{Acknowledgments}

We thank J. Achim, the Rheine-Zoo Director, for allowing and facilitating this work; G. Mancini, A. Leone, and V. Murianni for collaboration in the data collection. Thanks are due to W. Marzemino for his important clarifying input in discussing results. We thank Roger Mundry for his $\mathrm{R}$ scripts, which were dramatically useful during the statistical analysis. We wish to thank $\mathrm{C}$. Karmis, C. Girard-Buttoz and one anonymous reviewer for the accurate revision of the manuscript. This research was supported by private funding and it complies with current laws of Italy and Germany. Author Contributions: E.P. designed the experiment; V.P. collected the data. E.P., M.G. and V.P. analyzed the data. All authors contributed to the writing of the manuscript.

\section{References}

Aureli, F., \& Schaffner, C. M. (2007). Aggression and conflict management at fusion in spider monkeys. Biology Letters, 3, 147-149. doi:10.1098/rsbl.2007.0041 
Barr, D. J., Levy, R., Scheepers, C., \& Tily, H. J. (2013). Random effects structure for confirmatory hypothesis testing: keep it maximal. Journal of Memory and Language, 68, 255-278. doi: 10.1016/j.jml.2012.11.001

Barrett, L., Halliday, J., \& Henzi, S. P. (2006). The ecology of motherhood: the structuring of lactation costs by Chacma baboons. Journal of Animal Ecology, 75, 875-886.

Bates, D., Mächler, M., Bolker, B., \& Walker, S. (2015). Fitting Linear Mixed-Effects Models using lme4. Journal of Statistical Software, 67, 1-48. doi: 10.18637/jss.v067.i01

Beehner, J. C., \& Bergman, T. J. (2008). Infant mortality following male takeovers in wild geladas. American Journal of Primatology, 70, 1152-1159. doi 10.1002/ajp.20614

Bernstein, I. S. (1975). Activity patterns in a gelada monkey group. Folia Primatologica, 23, 50-71 doi:10.1159/000155661.

Boeving, E. R., Belnap S. C., \& Nelson E. L. (2017). Embraces are lateralized in spider monkeys (Ateles fusciceps rufiventris). American Journal of Primatology, 79, doi:10.1002/ajp.22654.

Bramblett, C. A. (1970) Coalitions among gelada baboons. Primates, 11, 327-333.

Cheney, D. L., Seyfarth, R. M., \& Silk, J. B. (1995). The role of grunts in reconciling opponents and facilitating interactions among adult female baboons. Animal behaviour, 50, 249-257. doi: 0003-3472/95/070249+09 \$12.00/0

Clay, Z., \& de Waal, F. B. M. (2013). Bonobos respond to distress in others: consolation across the age spectrum. PLoS ONE, 8, e55206. doi: 10.1371/journal.pone.0055206

Colmenares, F. (1991). Greeting behaviour between male baboons: oestrous females, rivalry and negotiation. Animal Behaviour, 41, 49-60.

Colmenares, F., Hofer, H., \& East, M. L. (2000). Greeting ceremonies in baboons and hyenas. In F. Aureli, \& F. B. M. de Waal (Eds.), Natural conflict resolution (pp. 94-96). Los Angeles, US: University of California Press. 
de Vries, H., Stevens, J. M. G., \& Vervaecke, H. (2006). Measuring and testing steepness of dominance hierarchies. Animal Behaviour, 71, 585-592. doi 10.1016/j.anbehav.2005.05.015 de Waal, F. B. M. (1996). Conflict as negotiation. In W. C. McGrew, L. F. Marchant, \& T. Nishida (Eds.), Great apes society (pp. 159-172). New York, US: Cambridge University Press.

de Waal, F. B. M. (2000). The first kiss: foundations of conflict resolution research. In F. Aureli, \& F. B. M. de Waal (Eds.), Natural conflict resolution (pp. 15-33). Los Angeles, US: University of California Press.

de Waal, F. B. M. (2008). Putting the altruism back into altruism: The evolution of empathy. Annual Review of Psychology, 59, 279-300. doi: 10.1146/annurev.psych.59.103006.093625

de Waal, F. B. M. (2012). Empathy in primates and other mammals. In J. Decety (Ed.), EmpathyFrom bench to bedside (pp. 87-106). Massachusetts, US: the MIT Press.

Dobson, A. J. (2002). An Introduction to Generalized Linear Models. $2^{\text {nd }}$ edition. Boca Raton, FL: Chapman and Hall/CRC Press.

Dunbar, R. I. M. (1983). Structure of gelada baboon reproductive units II. Social relationship between reproductive females. Animal Behaviour, 31, 556-564.

Dunbar, R. I. M. (2014). Reproductive decisions: an economic analysis of gelada baboon social strategies. Princeton University Press. Pp. 276.

Dunbar, R. I. M., \& Dunbar, E. P. (1975). Social dynamics of gelada baboons. Contributions to Primatology, 6, 1-157.

Dunbar, R. I. M., Barrett, R., \& Lycett, J. (2005). Evolutionary psychology, a beginner's guide. Oxford, UK: One World Books.

Dunbar, R. I. M., Hannah-Stewart L., \& Dunbar, P. (2002). Forage quality and the costs of lactation for female gelada baboons. Animal Behaviour, 64, 801-805. doi:10.1006/anbe.2002.1972.

Estienne, V., Stephens, C., \& Boesch, C. (2017). Extraction of honey from underground bee nests by central African chimpanzees (Pan troglodytes troglodytes) in Loango National Park, 
Gabon: Techniques and individual differences. American journal of primatology, 79, 999922672. doi: 10.1002/ajp.22672.

Feldman, R., Weller, A., Zagoory-Sharon, O., \& Levine, A. (2007). Evidence for a neuroendocrinological foundation of human affiliation. Psychological Science, 18, 965-970. doi: $10.1111 / \mathrm{j} .1467-9280.2007 .02010 . x$

Ferrari, P. F., Paukner, A., Ionica, C., \& Suomi, S.J. (2009). Reciprocal face-to-face communication between rhesus macaque mothers and their infants. Current Biology, 19, 1768-1772. doi 10.1016/j.cub.2009.08.055

Forsell, L. M., \& Åström, J. A. (2012). Meanings of hugging: from greeting behavior to touching implications. Comprehensive Psychology, 1, 13.

Forstmeier, W., \& Schielzeth, H. (2011). Cryptic multiple hypotheses testing in linear models: Overestimated effect sizes and the winner's curse. Behavioral Ecology and Sociobiology, 65, 47-55. https://doi.org/10.1007/s00265-010-1038-5

Fox, J., \& Weisberg, S. (2011). An R Companion to Applied Regression, 2nd Edn. Thousand Oaks, CA: SAGE Publications, Inc.

Frank, R. H. (2002). Altruism in competitive environments. In: R. J. Davidson, \& A., Harrington (Eds.), Visions of compassion (pp. 182-211). New York, US: Oxford University Press.

Frank, R., Silk, J. B. (2009). Grooming exchange between mothers and non-mothers: the price of natal attraction in wild baboons (Papio anubis). Behaviour, 136, 889-906. doi:10.1163/156853908X396656

Fujisawa, K. K., Kutsukake, N., \& Hasegawa, T. (2006). Peacemaking and consolation in Japanese preschoolers witnessing peer aggression. Journal of Comparative Psychology, 120, 48-57.

Furuichi, T. (2011). Female contributions to the peaceful nature of bonobo society. Evolutionary Anthropology, 20, 131-142. doi: 10.1002/evan.20308. 
476 Girard-Buttoz, C., Heistermann, M., Rahmi, E., Agil, M., Fauzan, P. A., \& Engelhardt, A. (2014). Costs of and investment in mate-guarding in wild long-tailed macaques (Macaca fascicularis): influences of female characteristics and male-female social bonds. International Journal of Primatology, 35, 701-724. doi: 10.1007/s10764-014-9775-3

Hamilton, W. D. (1964). The genetical evolution of social behaviour. I. Journal of theoretical biology, 7, 1-16.

Henzi, S. P. \& Barrett, L. (2002). Infants as a commodity in a baboon market. Animal Behavior, 63, 915-921. doi:10.1006/anbe.2001.1986

Henzi, S.P., \& Barrett, L. (2003). Evolutionary ecology, sexual conflict and behavioral differentiation among baboon populations. Evolutionary Anthopology, 12, 217-230.

Hertenstein, M. J., Keltner, D., App, B., Bulleit, B. A., \& Jaskolka, A. R. (2006). Touch communicates distinct emotions. Emotion, 6, 528-533. doi: 10.1037/1528-3542.6.3.528

Kawai, M., Dunbar, R. I. M., Ohsawa, H., \& Mori, U. (1983). Social organization of gelada baboons: social units and definitions. Primates, 24, 13-24.

Kutsukake, N., Suetsugu, N., \& Hasegawa, T. (2006). Pattern, distribution, and function of greeting behavior among black-and white colobus. International Journal of Primatology, 27, 12711291. doi: 10.1007/s10764-006-9072-X

le Roux, A., Beehner, J. C., \& Bergman, T. J. (2011). Female philopatry and dominance patterns in wild geladas. American Journal of Primatology, 73, 422-430.

Levine, A., Zagoory-Sharon, O., Feldman, R., \& Weller, A. (2007). Oxytocin during pregnancy and early postpartum: individual patterns and maternal-fetal attachment. Peptides, 28, 11621169. doi:10.1016/j.peptides.2007.04.016

Light, K. C, Grewen, K. M., \& Amico, K. A. (2005). More frequent partner hugs are linked to higher oxytocin levels, lower blood pressure, and heart rate in premenopausal women. Biological Psychology, 69, 5-21. doi:10.1016/j.biopsycho.2004.11.002 
Lynch Alfaro, J. (2008). Scream-embrace displays in wild black-horned capuchin monkeys. American Journal of Primatology, 70, 551-559. doi: 10.1002/ajp.20528

Maestripieri, D. (2001). Is there mother-infant bonding in primates? Developmental Review, 21, 93120. doi:10.1006/drev.2000.0522

Mancini, G., \& Palagi, E. (2009) Play and social dynamics in a captive herd of gelada baboons (Theropithecus gelada). Behavioural Processes, 82, 286-292. doi:10.1016/j.beproc.2009.07.007

McDaniel, E., \& Andersen, P.A. (1998). International patterns of interpersonal tactile communication: a field study. Journal of Nonverbal Behavior, 22, 59-75. 10.1023/A:1022952509743

McFarland, R., \& Majolo, B. (2013). Coping with the cold: predictors of survival in wild Barbary macaques, Macaca sylvanus. Biology Letters, 9, 20130428. doi:10.1098/rsbl.2013.0428

Mori, A., Belay, G., \& Iwamoto, T. (2003). Changes in unit structures and infanticide observed in Arsi geladas. Primates, 44, 217-223. 10.1007/s10329-002-0013-9

Mundry, R. (2011). Issues in information theory-based statistical inference-a commentary from a frequentist's perspective. Behavioral Ecology and Sociobiology, 65, 57-68. https://doi.org/10.1007/s00265-010-1040-y

Mundry, R., Nunn, C. L., Martins, A. E. E. P., \& Whitlock, E. M. C. (2009). Stepwise Model Fitting and Statistical Inference: Turning Noise into Signal Pollution. The American Naturalist, 173, 119-123. https://doi.org/10.1086/593303

Okamoto, K., Agetsuma, N., \& Kojima, S. (2001). Greeting behavior during party encounters in captive chimpanzees. Primates, 42, 161-165. 10.1007/BF02558143

Palagi E. 2018. Not just for fun! social play as a springboard for adult social competence in human and non-human primates. Behavioral Ecology and Sociobiology, 72, 90. doi:10.1007/s00265-018-2506-6. 
Palagi, E., Leone, A., Demuru, E., Ferrari, P. F. (2018) High-ranking geladas protect and comfort others after conflicts. Scientific Reports, 8, 15291. doi.org/10.1038/s41598-018-33548-y

Palagi, E., Leone, A., Mancini, G., \& Ferrari, P. F. (2009). Contagious yawning in gelada baboons as a possible expression of empathy. Proceeding of the National Academy of Science USA, 106, 19262-19267. doi: 10.1073/pnas.0910891106

Pallante, V., Stanyon, R., \& Palagi, E. (2016). Agonistic support towards victims buffers aggression in geladas (Theropithecus gelada). Behaviour, 153, 1217-1243.

Palombit, R. A., Seyfarth, R. M., \& Cheney, D.L. (1997). The adaptive value of "friendships" to female baboons: experimental and observational evidence. Animal Behaviour, 54, 599-614. doi:10.1006/anbe.1996.0457

Palombit, R.A., Cheney, D.L., Fischer, J., Johnson, S., Rendall, D., Seyfarth, R.M., \& Silk, J.B. (2000). Male infanticide and defence of infants in wild chacma baboons. In C.P. van Schaik, \& C. Janson (Eds.), Infanticide by Males and its Implications (pp. 123-152). Cambridge: Cambridge University Press.

Pastor-Nieto, R. (2001). Grooming, kinship and co-feeding in captive spider monkeys (Ateles geoffroyi). Zoo Biology, 20, 293-303.

Rebecchini, L., Schaffner, C.M., \& Aureli, F. (2011). Risk is a component of social relationships in spider monkeys. Ethology, 117, 691-699. DOI: 10.1111/j.1439-0310.2011.01923.x

Schaffner, C. M., \& Aureli, F. (2005). Embraces and grooming in captive spider monkeys. International Journal of Primatology, 26, 1093-1105. doi: 10.1007/s10764-005-6460-6

Schino, G., Scucchi, S., Meastripieri, D., \& Turillazzi, P. G. (1988). Allogrooming as a tensionreduction mechanism: a behavioural approach. American Journal of Primatology, 16, 4350. doi: 10.1002/ajp.1350160106 
Seyfarth, R. M., \& Cheney, D.L. (2013). Affiliation, empathy, and the origins of theory of mind. Proceeding of the National Academy of Science, 110, 10349-10356. doi: $10.1073 /$ pnas. 1301223110

Silk, J. B., Alberts, S. C., \& Altmann, J. (2003). Social bonds of female baboons enhance infant survival. Science, 302, 1231-1234.

Silk, J. B., Rendall, D., Cheney, D. L., \& Seyfarth, R. M. (2003). Natal attraction in adult female baboons (Papio cynocephalus ursinus) in the Moremi Reserve, Botswana. Ethology, 109, $627-644$.

Silk, J. B., Seyfarth, R. M., Cheney, D. L. (2016) Strategic use of affiliative vocalizations by wild female baboons. PLoS ONE, 11, e0163978. doi:10.1371/journal.pone.0163978

Simpson, E. A., Sclafani, V., Paukner, A., Hamel, A. F., Novak, M. A., Meyer, J. S., Suomi, S. J., \& Ferrari, P. F. (2014). Inhaled oxytocin increases positive social behaviors in newborn macaques. Proceeding of the National Academy of Science, 111, 6922-6927. doi: $10.1073 /$ pnas. 1402471111

Slater, K.Y., Schaffner, C.M., \& Aureli, F. (2007). Embraces for infant handling in spider monkey: evidence for a biological market? Animal Behaviour, 74, 455-461.

Smuts, B. B. (1985). Sex and Friendship in Baboons. New York: Aldine.

Smuts, B. B., \& Watanabe, J. M. (1990). Social relationships and ritualized greetings in adult male baboons (Papio cynocephalus anubis). International Journal of Primatology, 11, 147-172.

Snyder-Mackler, N., Beehner, J. C., \& Bergman, T. J. (2012). Defining higher levels in the multilevel societies of geladas (Theropithecus gelada). International Journal of Primatology, 33, 1054-1068.

Stern, D. N. (1985). The interpersonal world of the infant: a view from psychoanalysis and developmental psychology. New York, US: Basic Books. 
Strier, K. B., Carvalho, D. S., \& Bejar, N. O. (2000). Prescription for peacefulness. - In F. Aureli, \& F. B. M. de Waal (Eds.), Natural conflict resolution (pp. 94-96). University of California Press, Los Angeles, p. 315-317.

Strier, K. B., Dib, L. T., \& Figueira, J. E. C. (2002). Social dynamics of male muriquis (Brachyteles arachnoids hypoxanthus). Behaviour, 139, 315-342. doi: 10.1163/156853902760102690

Symington, M. M. (1987). Sex ratio and maternal rank in wild spider monkeys: when daughters disperse. Behavioral Ecology and Sociobiology, 20, 421-425. https://doi.org/10.1007/BF00302985

Thierry, B. (1984). Clasping behaviour in Macaca tonkeana. Behaviour, 89, 1-28. doi: $10.1163 / 156853984 X 00010$

Trevarthen, C. (1974). Conversation with a two-month-old. New Scientist, 2, 230-235.

Trevarthen, C. (1980). The foundation of intersubjectivity: development of interpersonal and cooperative understanding in infants. In D. Oslon (Ed.), The social foundation of language and thought (pp. 316-342), New York, US: Norton.

Tronick, E. Z. (1989). Emotions and emotional communication in infants. American Psychologist, 44, 112-119. http://dx.doi.org/10.1037/0003-066X.44.2.112

Whitham, J. C., \& Maestripieri, D. (2003). Primate rituals: the function of greetings between male Guinea baboons. Ethology, 109, 847-859. doi: 10.1046/j.0179-1613.2003.00922.x

\section{Figure legends}

Figure 1. The different kinds of gelada embraces. The Frontal Embrace (FE) consists in putting one or both arms round neck/chest of the other, who responds in the same way (Figure 1a). The Side Embrace (SE) consists in putting one arm over and one arm under the shoulder of the other 
598

599 600 601 602 603 604 605 606 607 608 609 610 611 612 613 614 615 616

individual while rotating the trunks in opposite directions (Figure 1b). Both FE and SE involve a face-to-face and chest-to-chest interaction between the embracers who show a reciprocal behavior. The Posterior Embrace (PE) consists in putting the arms around the back/waist of the conspecific and posing a cheek on it (Figure 1c). This kind of embracing is obviously not reciprocated.

Figure 2. Scatter plot showing the frequency of Frontal and Side Embracing $(\mathrm{FE}+\mathrm{SE})$ as a function of the relationship quality (social bonding) of the dyads involved.

Figure 3. The graph shows the frequency of Frontal and Side Embracing $(\mathrm{FE}+\mathrm{SE})(\mathrm{mean} \pm \mathrm{SE})$ as a function of motherhood condition.

Video S1 - The video shows two adult females with their black infants. At 00:01, the female on the left lip-smacks towards the female on the right side. At 00:02 the female on the left side initiates a Frontal Embracing behavior (FE). At 00:04 the female on the left side stands up and the two females initiate a face-to-face interaction while embracing each other. One of the black infants is looking at them. At 00:06 the female who initiated the embracing interaction begins to groom the female on the right.

Video S2 - The video shows two adult females sitting in contact. At 00:01, the female on the left side initiates a Side Embracing (SE) with the female on the right side. At 00:02, the female on the right side lip-smacks towards the other female and reciprocate her embrace. At 00:10 the female on the left side, who had initiated the embrace, begins to groom the other female. 